\title{
Limited-Distance Pollen Dispersal and Low Paternal Diversity in a Bird-Pollinated Self-Incompatible Tree
}

OPEN ACCESS

Edited by: Stefan Wanke,

Technical University Dresden,

Germany

Reviewed by:

Sissi Lozada Gobilard,

Tel Aviv University, Israel

Alyssa Stewart,

Mahidol University, Thailand

*Correspondence:

Ming-Xun Ren

renmx@hainanu.edu.cn

Specialty section:

This article was submitted to Plant Systematics and Evolution,

a section of the journal

Frontiers in Plant Science

Received: 31 October 2021

Accepted: 25 January 2022

Published: 25 February 2022

Citation:

Xiang $W$-Q, Malabrigo $P L \mathrm{~J}$,

Tang $L$ and Ren M-X (2022)

Limited-Distance Pollen Dispersal and Low Paternal Diversity in a

Bird-Pollinated Self-Incompatible

Tree. Front. Plant Sci. 13:806217.

doi: $10.3389 /$ fpls.2022.806217

\author{
Wen-Qian Xiang ${ }^{1,2}$, Pastor L. Malabrigo Jr. ${ }^{3}$, Liang Tang ${ }^{1,2}$ and Ming-Xun Ren ${ }^{1,2 *}$ \\ ' Key Laboratory of Ministry of Education for Genetics and Germplasm Innovation of Tropical Special Trees and Ornamental \\ Plants, Hainan University, Haikou, China, ${ }^{2}$ Center for Terrestrial Biodiversity of the South China Sea, Hainan University, \\ Haikou, China, ${ }^{3}$ Department of Forest Biological Sciences, College of Forestry and Natural Resources, University of the \\ Philippines Los Baños, Los Baños, Philippines
}

Bird pollination in Asia is regarded as an uncommon phenomenon and, therefore, only a few investigations on mating pattern and paternity in fruits of Asian bird-pollinated plants have been conducted. Here, we examined spatial genetic structure, pollen dispersal, and multiple paternity in a natural population of Bombax ceiba (B. ceiba) (Malvaceae) in Hainan Island, South China, using simple sequence repeat (SSR) markers. A low genetic diversity $\left(H_{e}=0.351 \pm 0.0341\right.$ and $0.389 \pm 0.043$, respectively, for adults and offspring) and bottleneck effects were observed. Genetic kinship was significant within $400 \mathrm{~m}$ or in 1,800-3,800 $\mathrm{m}$. Both the mating pattern and paternity analysis confirmed obligate xenogamy and a low multiple paternity in $B$. ceiba. There was a strongly negative relationship between the frequency of matings and the distance between mating pairs. The average pollen dispersal distance was $202.89 \pm 41.01 \mathrm{~m}$ (mean $\pm \mathrm{SE}$ ) and the farthest distance of $>1 \mathrm{~km}$ was recorded. Realized mating events showed an extremely leptokurtic distribution within 1,200 m, suggesting that the pollen dispersal distance was consistent with the optimal foraging theory of generalist birds such as Zosterops spp. and Pycnonotus spp. Paternity per tree ranged from two to six and the average effective number of pollen donors per maternal plant was 3.773, suggesting a low level of paternity diversity as compared to other bird-pollinated plants. We concluded that optimal foraging behavior by generalist birds could explain the leptokurtic pollen dispersal distribution and predominantly near-neighbor matings in B. ceiba. The limited pollen dispersal distance and low multiple paternity were consistent with low fruit setting rate $(3.27 \pm 0.93 \%)$ in this self-incompatible tree, which was caused mainly by the restricted flight distance of birds and human disturbances. Low genetic diversity and significant spatial genetic structure might have largely resulted from logging and human collection of fruits.

Keywords: mating system, paternity analysis, pollen flow, microsatellite DNA, genetic diversity, Bombacoideae 


\section{INTRODUCTION}

Birds are one of the most diverse group of ecosystem service providers. More than 900 bird species pollinate members of ca. 500 of the 13,500 vascular plant genera, making bird pollination an essential component of the ecosystem (Sekercioglu, 2006). This pollination function that birds provide is mainly an outcome of their foraging behavior. Birds act as mobile links that transfer pollen within and between plant populations (Bezemer et al., 2016). Often times, birds could be more effective pollinators than insects such as honeybees because their greater potential mobility (Southerton et al., 2004; Coimbra et al., 2020). In Myrtaceae, Proteaceae, Polemoniaceae, and other bird-pollinated species, the pollen dispersal distance within the population is usually within $200 \mathrm{~m}$ (Krauss et al., 2009; Bezemer et al., 2016). At larger scales, birds that undertake long distance movements in pursuit of patchy nectar supplies are more capable of mediating pollen dispersal distances of several kilometers when populations are fragmented (Byrne et al., 2007). Further, high energy needs may promote birds to visit several plants on a single foraging bout, which in combination with their ability to travel long distances help in promoting xenogamous pollination. Moreover, pollination by highly mobile and long-distance flying birds can reduce the risk of genetic erosion associated with demographic bottlenecks and genetic drifts (Bezemer et al., 2016) and also increases the resilience of naturally fragmented and genetically insular plant populations by buffering genetic erosion (Breed et al., 2015).

Bird pollination research has largely focused on Scrophulariaceae, Labiatae, Costaceae, and Proteaceae families of plants in South America, Africa, and Australia (Krauss et al., 2017). This may be attributed to the highest diversity of effectively specialized nectarivorous birds in tropics and in the Southern Hemisphere, which include sunbirds (African and Asian tropics), honeyeaters, lorikeets (eastern Australia and New Guinea), and hummingbirds (the Andes and central American mountains). For a long time, bird pollination systems were generally overlooked in Asia because sunbirds (Nectariniidae) are the only specialized nectar-feeding birds (Krauss et al., 2017) and only few plant species are pollinated by specialist nectar-feeding birds. However, increasing number of studies for almost two decades show that generalist birds act as alternative pollinators in Asia (Roguz et al., 2018). Remarkably, generalist passerines have been demonstrated as the most effective pollinators for winter flowering plants in regions where sunbirds are absent, especially in dry seasons and in the islands (Chen et al., 2019). These include species such as Fritillaria imperialis (Roguz et al., 2021), Firmiana spp. (Huang et al., 2018), Rhodoleia spp. (Gu et al., 2010), Woodfordia spp. (Raju, 2005), Rhododendraceae (Song et al., 2019), and Bombacoideae (Xiang and Ren, 2019).

Previous studies have mostly focused on observing pollination behaviors or analyzing the reproductive ecology of tree species pollinated by generalist birds (Huang et al., 2018). It is conspicuous that such a pollination system is relatively common in Asia and on tropical islands. Yet, questions related to mating behavior, pollen dispersal, and genetic structure of plant species pollinated by generalist birds remain unexplored.
Under extreme environmental conditions such as dry weather (Stiles, 1978), on island habitats (Chen et al., 2019), and due to increasing human interference (Byrne et al., 2007), a better understanding of the mating system of generalist-pollinated species and of how birds influence mating patterns is further warranted. Identifying the underlying behavioral mechanisms of bird pollinators responsible for pollen movement would deepen the understanding of evolutionary and ecological consequences of bird pollination for plant mating.

The tropical tall tree species of Bombax ceiba (B. ceiba) L. (Bombacoideae, Malvaceae) is an umbrella species in dry and hot forest areas of Asia because they can provide food, shelter, roosting, and breeding sites to a large number of birds as well as insects and form the major structural and functional basis of forest ecosystems (Jain et al., 2011). It is found in temperate and tropical regions of Asia such as India, China-Indochina Peninsula, Indonesia, Malaysia, Philippines, Sri Lanka, and Northern Australia. B. ceiba is large deciduous trees, distributed mainly in arid-hot valleys, roadsides, and open areas in tropical and subtropical Asia (Barwick, 2004; Zhou et al., 2015). In southern China, it is a significant economic tree species and a tourist resource, which is often disturbed by urbanization, felling, and other human activities. B. ceiba is a typical bird-pollinated plant with big flowers that have bright upward corolla and copious dilute nectar (Raju et al., 2005). The flowering of B. ceiba peaks during late February and early March, which is the dry season in southern China, especially in Hainan Island (data from National Meteorological Information Center). ${ }^{1}$ At this time, there are only limited number of plants that are flowering in southern China and the copious dilute nectar of B. ceiba acts as the main food and a safe water resource for generalist birds. Li et al. (2016) and Xiang and Ren (2019) confirmed that migratory omnivorous (generalist) birds, such as those of Zosteropidae, Sturnidae, and Laniidae families, were the frequent and efficient pollinators of B. ceiba during the peak flowering in China, especially in Hainan Island and dry-hot valleys of Yunnan (Figure $\mathbf{1}$ and Table 1).

In this study, we analyzed genetic diversity, mating system, gene flow, and multiple paternity of B. ceiba that are pollinated by generalist birds in the Hainan Island of China. Specifically, this study addresses the following two questions: (i) What is the mating system and pollen dispersal of B. ceiba? and (ii) How do generalist birds affect genetic diversity and mating patterns? We hypothesize that: (i) limited-distance pollen dispersal and low paternal diversity may be due to high density of $B$. ceiba individuals and bird habits such as the restricted flight distance of birds and optimum foraging behavior of birds and (ii) pollination by generalist birds may result in high outcrossing rate, but low genetic diversity in $B$. ceiba due to human disturbances.

\section{MATERIALS AND METHODS}

\section{Study Site}

This study was conducted on a wild population of B. ceiba trees that were located at the forest margins near the Bawangling

\footnotetext{
${ }^{1}$ http://data.cma.cn/
} 


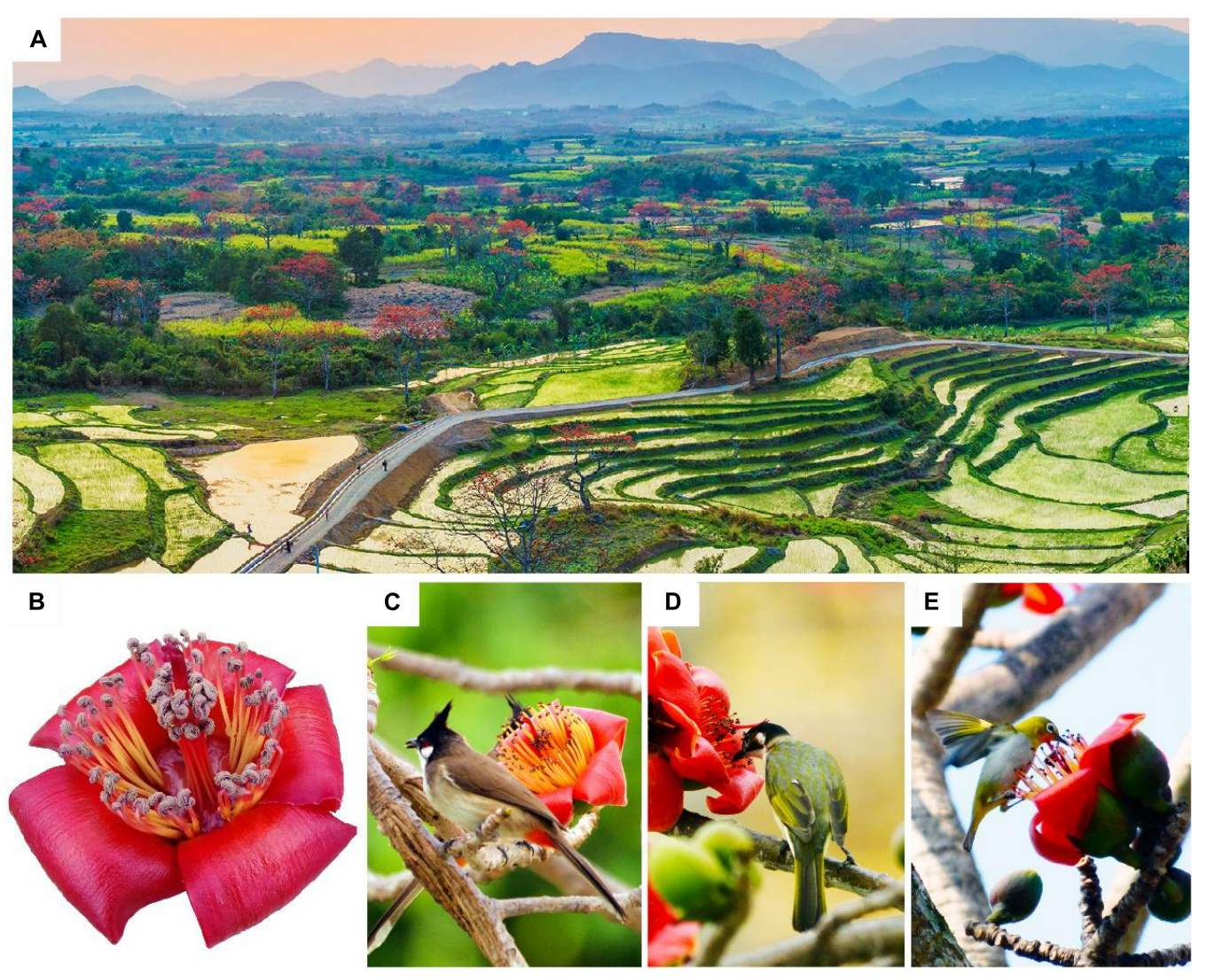

FIGURE 1| Bombax ceiba (B. ceiba) in Hainan Island. (A) A flowering population in west Hainan Island. (B) A representative picture of floral syndromes. Note that stamens are in two whorls. B. ceiba flowers were mainly visited by Pycnonotus jocosus (C), Brachypodius atriceps, (D) and Zosterops palpebrosus (E).

TABLE 1 | The different types of birds that visit Bombax ceiba as well as their frequency of visits, habits, and flight capability.

\begin{tabular}{|c|c|c|c|c|c|}
\hline Species & $\begin{array}{l}\text { Group } \\
\text { members }\end{array}$ & $\begin{array}{c}\text { Visit frequency } \\
\left(\text { Visits }^{*} \text { tree }^{-1 *} h^{-1}\right)\end{array}$ & $\begin{array}{l}\text { Long distance flight } \\
\text { capability (> } 5 \mathrm{~km})\end{array}$ & $\begin{array}{c}\text { Home range impacts } \\
\text { on axial variance }\end{array}$ & References \\
\hline Zosterops palpebrosus & $10-15$ & $4.98 \pm 0.72$ & Yes & $\begin{array}{l}\text { Typically } \\
<3 \text { ha }\end{array}$ & $\begin{array}{l}\text { Zhao, 2001; Higgins } \\
\text { et al., } 2006\end{array}$ \\
\hline Pycnonotus xanthorrhous & $3-5$ & $0.47 \pm 014$ & No & No data & Zhao, 2001 \\
\hline Pycnonotus jocosus & $3-10$ & $0.41 \pm 0.15$ & No & No data & Zhao, 2001 \\
\hline Acridotheres cristatellus & $2-4$ & $0.20 \pm 0.07$ & Yes & No data & Zhao, 2001 \\
\hline Lanius sp. & $1-2$ & $0.67 \pm 0.16$ & Yes & $\begin{array}{l}\text { Typically } \\
<3 \text { ha }\end{array}$ & $\begin{array}{c}\text { Zhao, 2001; Higgins } \\
\text { and Peter, } 2002\end{array}$ \\
\hline Parus sp. & $3-5$ & $0.23 \pm 0.08$ & No & No data & Zhao, 2001 \\
\hline
\end{tabular}

National Nature Reserve, west Hainan Island $\left(18^{\circ} 53^{\prime}-19^{\circ} 30^{\prime} \mathrm{N}\right.$, $108^{\circ} 38^{\prime}-109^{\circ} 17^{\prime} \mathrm{E}$; Figures 1, 2). B. ceiba is a common species in this region and this study site contains the most concentrated areas of $B$. ceiba in Hainan Island. Studied population is located across Baotie to Baoshan villages, which are connected by a rural road and are surrounded by Hevea brasiliensis. The total area of this study site is 2,100 hectares (Figure 2) and the B. ceiba trees were distributed on the paddy fields and sugarcane fields. The area is dominated by a monsoon climate, marked with a distinct wet (May to October) and a dry season (November to next April), and witnesses the lowest annual precipitation (about $1,700 \mathrm{~mm}$ ) on Hainan Island. The annual average temperature is about $24.3^{\circ} \mathrm{C}$ (data from Meteorological Service of Hainan). ${ }^{2}$

\section{Study Species}

The flowering season of $B$. ceiba is from early February to late March and the life span of one single flower is 7-12 days. At midnight, hundreds of the mature buds begin to open. B. ceiba

\footnotetext{
${ }^{2}$ http://www.hainanqx.cn
} 
A

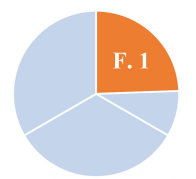

$\mathrm{R} 1\left(n_{c}=3, n_{s}=45\right)$

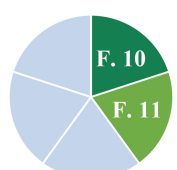

$\mathrm{R} 12\left(n_{c}=5, n_{s}=75\right)$

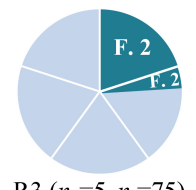

$\mathrm{R} 3\left(n_{c}=5, n_{s}=75\right)$

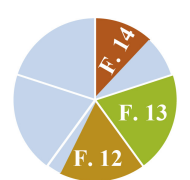

$\mathrm{R} 13\left(n_{c}=5, n_{s}=75\right)$

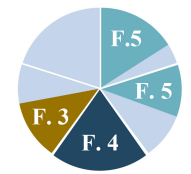

$\mathrm{R} 5\left(n_{c}=5, n_{s}=75\right)$
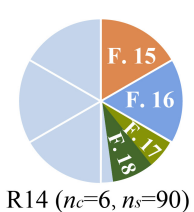

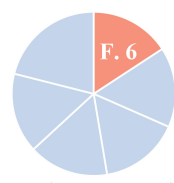

$\mathrm{R} 8\left(n_{c}=6, n_{s}=75\right)$

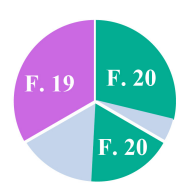

$\mathrm{R} 15\left(n_{c}=3, n_{s}=45\right)$

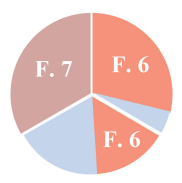

$\mathrm{R} 9\left(n_{c}=3, n_{s}=45\right)$

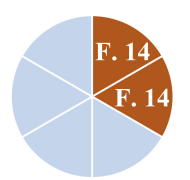

$\mathrm{R} 16\left(n_{c}=6, n_{s}=90\right)$

B

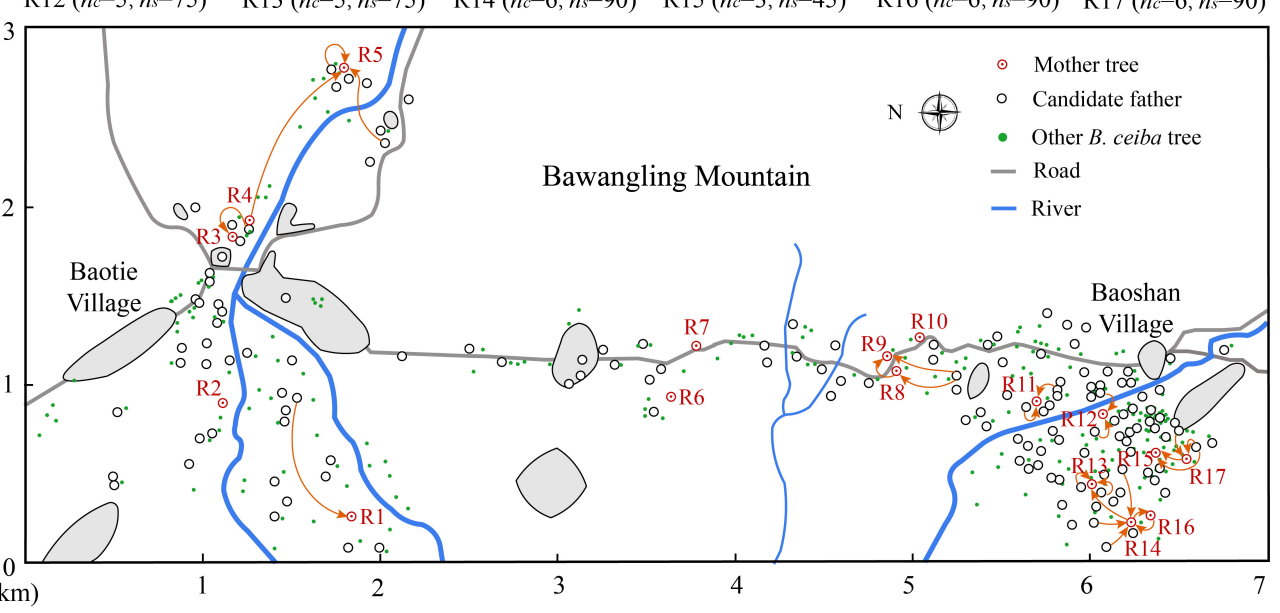

FIGURE 2 | Pollen flow and multiple paternity of $B$. ceiba. (A) Composition of fathers in individual trees. $n_{c}$, number of capsules analyzed in each tree; $n_{s}$, number of seeds analyzed in each tree; F, seedlings assigned father; different colors in the pie chart represent seedlings assigned to different fathers and gray color indicates seedlings not assigned to a pollen parent within the study population. (B) Pollen flow of $B$. ceiba individuals in the study stand. The gray area represents buildings.

is a protandry plant and the anthers dehisce almost immediately after the flowers open and pollen activity was about $80 \%$. After anther dehiscence, the stigma becomes receptive and the function between the sexes overlapped. The staminate phase can last for about $30 \mathrm{~h}$, while the pistillate phase of $B$. ceiba can last around 3-4 days.

The capsule maturation period of $B$. ceiba in Hainan Island is between March and May. Capsules are ellipsoid and dehisce after the ripening. Many seeds are produced (about 200), which are obovate, smooth, and fibrous from outside and form fluffy spheres of seed coats. The seeds are located in the center of the sphere and are dispersed far away by the wind.

\section{Bird Observation and Hand-Pollination Treatments}

On around 10 consecutive sunny days, between 06:00 and 18:00 h in February 2018, the number and type of bird visits per day in the 10 blooming individuals were recorded and photographed everyday in studied population.

Hand-pollination experiments were conducted in the wild population to estimate mating systems of $B$. ceiba. Five pollination treatments were applied on different branches on four trees (Table 2): (1) Bagged only ( $n=20$ flowers), bagging mature buds without any hand pollination; (2) emasculation ( $n=20$ flowers), bagging mature buds and all the anthers were cutoff; (3) autogamy ( $n=20$ flowers), bagging mature buds and pollinated with pollen from the same flower; (4) geitonogamy $(n=20$ flowers), bagging emasculated mature buds and pollinated with pollen from the same plant; and (5) xenogamy ( $n=20$ flowers), bagging emasculated mature buds and pollinated with pollen from different $B$. ceiba trees. Fruit set of open pollination was observed from all the flowers on 17 individuals as control.

\section{Sample Collection}

A total of 378 adult individuals were recorded at this study site, of which 163 adults, including 17 mother trees, were randomly selected for experiments (Figure 2). To accurately

TABLE 2 | Fruit set in Bombax ceiba following hand-pollination treatments and natural pollination.

\begin{tabular}{lcc}
\hline Treatments & No. of trees or flowers & Percentage of fruit set \\
\hline Bagged only & 20 Flowers & 0 \\
Emasculation & 20 Flowers & 0 \\
Self-pollination & 20 Flowers & 0 \\
Geitonogamy & 20 Flowers & 0 \\
Xenogamy & 20 Flowers & 0.85 \\
Open pollination & 17 Trees & 0.03 \\
\hline
\end{tabular}


assess population size, pollen dispersal distances, and spatial genetic structure (SGS), 2BULU version $6.2 .1^{3}$ was used to obtain the global positioning system (GPS) coordinates of each plant and all the adults were mapped on this study site in 2018 (Figure 2). In late April 2018, two young leaves were collected from all the 163 experimental trees for genotyping. A total of 80 capsules were collected from 17 mother trees in early May 2018. Each tree (family) was composed of 3-7 fruits. In late May 2018, seeds from the same fruit were germinated in a culture dish. At a height of $6 \mathrm{~cm}$, at least 15 seedlings were selected from each fruit/culture dish and a total of 1,190 F1 seedlings were harvested for genotyping.

\section{Deoxyribonucleic Acid Extraction and Simple Sequence Repeat Genotyping}

Total genomic DNA was extracted from leaf tissue by using a modified cetyltrimethylammonium bromide (CTAB) protocol (Doyle, 1990). A total of 13 polymorphic expressed sequence tag (EST)-SSR markers developed by Ju et al. (2015) were applied to all the 1,353 samples (163 adults plus 1,190 seedlings) (Supplementary Table 1). SSR markers are co-dominant, polymorphic, randomly distributed markers in genomes, and are probably selectively neutral (Song et al., 2003). Therefore, SSR markers are widely used in studies of parentage, gene flow, genetic diversity, and population differentiation (Song et al., 2003; Wu et al., 2020).

Polymerase chain reaction amplification of primer pairs was performed with the Veriti 96-Well Thermal Cycler (Applied Biosystems, Foster City, California, United States) by using a $25-\mu 1$ reaction mixture containing $1 \mu \mathrm{l}$ of genomic DNA (50 $\mu \mathrm{g} / \mathrm{ml}$ stock), $1 \mu \mathrm{l}$ each of forward and reverse primers (10 $\mu \mathrm{M}$ stock), $12.5 \mu \mathrm{l}$ of PCR Master Mix, and $9.5 \mu \mathrm{l}$ of $\mathrm{ddH}_{2} \mathrm{O}$. Forward primers were labeled with a fluorescent dye [6-carboxyfluorescein (FAM), carboxytetramethylrhodamine (TAMRA), hexachlorofluorescein (HEX), or 6-carboxy-X-Rhodamine (ROX)]. PCR amplifications were performed as following: an initial denaturation step at $94^{\circ} \mathrm{C}$ for $5 \mathrm{~min}, 35$ cycles comprising of: (i) denaturation at $94^{\circ} \mathrm{C}$ for $30 \mathrm{~s}$, (ii) $45 \mathrm{~s}$ annealing at temperatures specified below, and (iii) extension at $72^{\circ} \mathrm{C}$ for $1 \mathrm{~min}$. This was followed by a final extension step at $72^{\circ} \mathrm{C}$ for $10 \mathrm{~min}$. The annealing temperature was $57^{\circ} \mathrm{C}$ for $\mathrm{BC} 1, \mathrm{BC} 3, \mathrm{BC} 4$, $\mathrm{BC} 8, \mathrm{BC} 9$, and $\mathrm{BC} 13$ and $60^{\circ} \mathrm{C}$ for $\mathrm{BC} 2, \mathrm{BC} 5, \mathrm{BC} 6, \mathrm{BC}, \mathrm{BC} 10$, $\mathrm{BC} 11$, and $\mathrm{BC} 12$. To test the utility of the primers, PCR products were detected on $1 \%$ agarose gels. Next, the PCR products were resolved on the ABI3730xl Genetic Analyzer (Applied Biosystems, Foster City, California, United States) with an internal lane standards (LIZ) (500) size standard. Fragment data were analyzed by using GeneMarker version 2.4.0 (Softgenetics LLC, State College, Pennsylvania, United States).

\section{Genetic Diversity}

The presence of null alleles was checked by using Micro-Checker version 2.2.3 (Van Oosterhout et al., 2004) and a departure from Hardy-Weinberg equilibrium (HWE) for all the loci was tested by using Genepop version 4.2 (Raymond and Rousset,

${ }^{3}$ https://www.2bulu.com/
1995). For each locus, the genetic diversity for all the sampled adults was characterized by the number of alleles per locus $\left(N_{a}\right)$, number of effective alleles $\left(N_{e}\right)$, observed heterozygosity $\left(H_{o}\right)$, expected heterozygosity $\left(H_{e}\right)$, and inbreeding coefficient $\left(F_{i s}\right)$. The total paternity exclusion probability of the first $[\operatorname{Pr}(E x 1)]$ and second parent $[\operatorname{Pr}(E \times 2)]$ was also estimated. These analyses were performed by using the Cervus version 3.0.7 program (Marshall et al., 1998).

We tested for signatures of genetic bottlenecks by using two tests available in Bottleneck version 1.3.2. ${ }^{4}$ The Wilcoxon signedrank test was used, as it has been determined as the most appropriate statistical test with respect to the number of loci employed and the number of sampled individuals per population (Piry et al., 1999). It is available in Bottleneck version 1.3.2 for two mutational models: the stepwise mutation model (SMM) and the two-phase model (TPM) (Di Rienzo et al., 1994). The second test is suitable for evaluating the allele frequency distribution. The alleles were classified into 10 frequency classes, which were then used to test whether the distribution followed the normal L-shaped form.

\section{Spatial Genetic Structure Analysis}

To investigate the SGS of $B$. ceiba adults established within the stand, we conducted spatial autocorrelation analyses based on pairwise kinship coefficients $\left(F_{i j}\right)$ between individuals (Loiselle et al., 1995) and against physical distances by using the SPAGeDi program version 1.5d (Hardy and Vekemans, 2002). Twelve distance classes were chosen to achieve the (best) uniform scale over populations as following: 0-200, 200-400, 400$600,600-800,800-1,000,1,000-1,200,1,200-1,800,1,800-3,800$, $3,800-5,000,5,000-5,400,5,400-5,800$, and 5,800-6,400 m. The statistical significance of the autocorrelation was tested by 10,000 random permutations with a $95 \% \mathrm{CI}$.

\section{Mating System Analysis}

Estimates of mean multilocus $\left(t_{m}\right)$ and single locus $\left(t_{s}\right)$ outcrossing rates, correlation of $t_{m}$ within progeny arrays $\left(r_{t}\right)$, and multilocus paternity correlation $\left(r_{p}\right)$ were calculated with the help of multilocus $\mathrm{t}$ and $\mathrm{r}$ (MLTR) win 3.4 (Ritland, 2002). The mean number of effective pollen donors $\left(N_{e p}\right)$ that participated in cross-pollination was estimated from the withinsibship correlated paternity $\left(r_{p}\right)$, which is defined as $N_{e p}=1 / r_{p}$. The program was run by using default parameters for the outcrossing rate $(t=0.9)$, parental inbreeding $(F=0.1)$, and paternity correlation $\left(r_{p}=0.1\right)$. The estimation of mating system indices was made by the expectation-maximization method to ensure convergence; 1,000 bootstraps were used to calculate SE.

\section{Paternity Analysis}

Paternity assignment was conducted by categorical allocation in Cervus version 3.0.7 (Kalinowski et al., 2007). Logarithm of odds (LOD) scores were calculated for all the sampled plants, as every reproductive individual in the population is a potential sire. LOD scores were calculated by determining the likelihood of assignment of a parent relative to the likelihood

${ }^{4}$ https://pypi.org/project/Bottleneck/ 
of arbitrary parents. The simulation parameters were as follows: 10,000 cycles, 380 candidate parents, 0.43 as the proportion of candidate parents sampled, 0.9935 as the proportion of loci typed, and 0.0125 as the rate of typing error (calculated from repeat genotyping). Strict confidence levels were set at $95 \%$ and relaxed confidence levels were set at $80 \%$.

Paternity assignment was used to calculate the realized outcrossing rate, multiple paternity per capsule, and realized pollen dispersal distances. Distributions of realized mating and potential mating under random pollinations were tested by using the Kolmogorov-Smirnov test and proportions test for each $100 \mathrm{~m}$ increment as well as for the overall study site (Siegel, 1956). Distances between maternal and potential sires represent a theoretical distribution of random mating and were calculated by taking the mean distances between each maternal and all the other plants and then averaging those values for each incremental $100 \mathrm{~m}$ distance class (Sokal and Rohlf, 1995). Thus, the proportion of potential mating events reflects the number of maternal/potential sire pairs that occur within each distance class. To standardize the population size and the density, realized pollen dispersal was also plotted against ranked distance between a maternal individual and all the potential sires. Ranked distance was calculated by assigning plant pairs (a value from 0 to 1,300). The resulting distribution was tested for kurtosis $(K)$ by using the kurtosis function in $\mathrm{R}$ ( $\mathrm{R}$ Core Team, 2013). Negative kurtosis indicates a flat data distribution (platykurtosis), positive kurtosis indicates a peaked distribution (leptokurtosis), and zero kurtosis indicates a normal distribution. A simple linear regression analysis was applied in $\mathrm{R}$ to test whether the proportion of outcross mating declined linearly with ranked distance, following the approach described by Krauss et al. (2009).

\section{RESULTS}

\section{Bird Observation}

At this study sites, $B$. ceiba flowers were pollinated by Zosterops palpebrosus (Z. palpebrosus), Pycnonotus xanthorrhous (P. xanthorrhous), Pycnonotus jocosus (P. jocosus), Acridotheres cristatellus, Sturnus sinensis, Lanius spp., and Parus spp. (Table 1). Among them, the visit frequency of $Z$. palpebrosus is the greatest $(4.98 \pm 0.72$ visits per tree per $\mathrm{h})$, while $P$. xanthorrhous, P. jocosus, and Parus spp. are resident birds (Table 1).

The results of hand-pollination treatments showed that $B$. ceiba fruited solely by xenogamy, with fruit set rate was $85 \pm 8.19 \%$ (Table 2). For open-pollinated flowers, the number of fruit produced per tree varied from 50 to 300 and the average fruit set rate for 17 trees was $3.27 \pm 0.93 \%$ (Table 2).

\section{Genetic Diversity}

Null alleles were not detected in any of the 13 microsatellite loci and a low genetic diversity was confirmed. The average number of alleles per locus was 3.62 for adults and 4.15 for F1 seedlings (Supplementary Table 2). The mean $H_{o}$ and $H_{e}$ were 0.285 and 0.351 among the adults and 0.343 and 0.389 among the seedlings, respectively (Supplementary Table 2).
The overall mean $F_{\text {is }}$ was $-0.170( \pm 0.074, \mathrm{SE})$ for the adults and -0.224 ( $\pm 0.084, \mathrm{SE})$ for the offspring, which indicated "heterozygote excess," but there was no significant difference between them $(P=0.638)$. In addition, $F_{i s}$ in adults and seedlings significantly differed from $0(P=0.025, P=0.019$, respectively). Eight loci in the adults and ten loci in the offspring showed significant deviation from $\operatorname{HWE}(P<0.05$; Supplementary Table 2). Although the calculated genetic diversity measures in the adults were lower than in the seedlings, the differences were not significant for $N_{a}(P=0.335), N_{e}(P=0.499), H_{o}$ $(P=0.271)$, and $H_{e}(P=0.494)$. Across all the 13 loci, the cumulative expected exclusion probability of the first $\operatorname{Pr}(E x 1)$ and second $\operatorname{Pr}(E x 2)$ parents, estimated from adults, was 0.9935 and 0.9999, respectively (Supplementary Table 2).

In the Wilcoxon signed-rank test, the adults $(n=163$, $P=0.305)$ and the offspring $(n=1,190, P=0.641)$ of $B$. ceiba were found not at mutation-drift equilibrium under the SMM. Under the TPM, the program detected a bottleneck signature for adults ( $n=163, P=0.034)$; however, the program did not find this signature for the offspring cohort $(n=1,190, P=0.372)$. However, the allele frequency distribution test showed a modeshift shape for the adults as well as the offspring of $B$. ceiba in Hainan population (Supplementary Figure 1).

\section{Spatial Genetic Structure}

Spatial genetic structure analysis, by using pairwise differentiation measures, showed significance in the first $(0-200 \mathrm{~m})$, second $(200-400 \mathrm{~m})$, and eighth distance classes $(1,800-3,800 \mathrm{~m})$, with a $F_{i j}$ value of $0.03615(P=0.027), 0.03270$ $(P=0.031), 0.2370(P=0.033)$, and $0.01813(P=0.017)$, respectively (Supplementary Figure 2 ). In the seventh $(1,200-$ $1,800 \mathrm{~m})$, tenth $(5,000-5,400 \mathrm{~m})$, eleventh $(5,400-5,800 \mathrm{~m})$, and twelfth distance classes $(5,800-6,400 \mathrm{~m}), F_{i j}$ was negative $(-0.00394,-0.00077,-0.00238$, and -0.00138 , respectively), but not significantly different from the expected value $(P>0.05)$.

\section{Mating System}

Multilocus outcrossing rates $\left(t_{m}\right)$ for 17 mother plants were equal to 1.000 (Table 3 ), strongly suggesting that all the seedlings were products of outcrosses. Biparental inbreeding rates $\left(t_{m}-t_{s}\right)$ ranged from -0.196 to 0.123 , with a mean $( \pm \mathrm{SE})$ value of $-0.063 \pm 0.017$ among F1 seedlings from 79 capsules (Table 3 ). The $t_{m}-t_{s}$ values of the F1 seedlings from capsule R3, R8, R9, R13, R16, and R17 were greater than 0 , indicating biparental inbreeding (Table 3 ).

Analysis of mating patterns revealed significant correlation in outcrossing rates among siblings $\left(r_{t}=-0.999 \pm 0.000\right)$. The estimated correlation of paternity $\left(r_{p}\right)$ was $0.265 \pm 0.024$, indicating that individuals in the family have the opportunity to share the same father (Table 4). The average effective number of pollen donors per maternal plant $\left(N_{e p}\right)$ was 3.773 . This showed that there was more than one male parent in F1 seedlings derived from a single capsule (Table 4 ).

\section{Paternity Analysis and Multiple Paternity}

Paternity assignments revealed the following results: of the 1,190 F1 seedlings, $376(31.6 \%)$ and 605 (50.8\%) seedlings were assigned to a single pollen parent in the population at the 95 and 
TABLE 3 | Mating system, multiple paternity, and outcrossing rate for 17 open-pollinated trees of Bombax ceiba.

\begin{tabular}{|c|c|c|c|c|c|c|c|c|c|}
\hline \multirow[t]{3}{*}{ Maternal plants } & \multirow{3}{*}{$\begin{array}{c}\text { Maternal } \\
\text { capsules } \\
\text { (total } \\
\text { capsules) }\end{array}$} & \multicolumn{3}{|c|}{ MLTR estimates } & \multicolumn{4}{|c|}{ Calculations based on CERVUS results } & \multirow{3}{*}{$\begin{array}{l}\text { Proportion } \\
\text { outcrossed }\end{array}$} \\
\hline & & \multirow[t]{2}{*}{$n$} & \multirow{2}{*}{$t_{m}$ (SE) } & \multirow{2}{*}{$t_{m}-t_{s}$ (SE) } & \multicolumn{2}{|r|}{$n$} & \multicolumn{2}{|c|}{ Number of different sires } & \\
\hline & & & & & Seeds & $\begin{array}{c}\text { Mean } \\
\text { seeds/capsule }\end{array}$ & $\begin{array}{l}\text { Mean/ } \\
\text { capsule }\end{array}$ & Total/ tree & \\
\hline $\mathrm{R} 1$ & $3(177)$ & 45 & $1.000(0.001)$ & $-0.063(0.006)$ & 11 & 3.7 & 2.00 & 2 & 1 \\
\hline $\mathrm{R} 2$ & $5(236)$ & 75 & $1.000(0.001)$ & $-0.113(0.026)$ & - & - & - & - & - \\
\hline R3 & $5(295)$ & 75 & $1.000(0.001)$ & 0.087 (0.032) & 18 & 3.6 & 1.50 & 2 & 1 \\
\hline R4 & $5(119)$ & 75 & $1.000(0.001)$ & $0.000(0.001)$ & - & - & - & - & - \\
\hline R5 & $5(415)$ & 75 & $1.000(0.001)$ & $-0.196(0.013)$ & 44 & 8.8 & 1.75 & 6 & 1 \\
\hline R6 & $3(191)$ & 45 & $1.002(0.001)$ & $-0.168(0.011)$ & - & - & - & - & - \\
\hline $\mathrm{R} 7$ & $5(116)$ & 75 & $1.000(0.001)$ & $-0.028(0.011)$ & - & - & - & - & - \\
\hline R8 & $6(223)$ & 95 & $1.000(0.001)$ & $0.019(0.023)$ & 15 & 2.1 & 1.00 & 2 & 1 \\
\hline $\mathrm{R} 9$ & $3(196)$ & 45 & $1.000(0.001)$ & $0.001(0.025)$ & 35 & 11.7 & 1.67 & 4 & 1 \\
\hline $\mathrm{R} 10$ & $3(310)$ & 45 & $1.002(0.001)$ & $-0.025(0.005)$ & - & - & - & - & - \\
\hline R11 & $5(203)$ & 75 & $1.000(0.001)$ & $-0.012(0.009)$ & 27 & 5.4 & 1.50 & 3 & 1 \\
\hline $\mathrm{R} 12$ & $5(198)$ & 75 & $1.000(0.001)$ & $0.000(0.001)$ & 30 & 6.0 & 1.00 & 3 & 1 \\
\hline $\mathrm{R} 13$ & $5(150)$ & 75 & $1.000(0.001)$ & $0.004(0.042)$ & 37 & 7.4 & 1.67 & 6 & 1 \\
\hline $\mathrm{R} 14$ & $6(427)$ & 90 & $1.000(0.001)$ & $-0.03(0.017)$ & 43 & 7.2 & 1.67 & 6 & 1 \\
\hline R15 & $3(240)$ & 45 & $1.000(0.001)$ & $-0.091(0.040)$ & 36 & 12.0 & 1.67 & 4 & 1 \\
\hline $\mathrm{R} 16$ & $6(326)$ & 90 & $1.000(0.001)$ & $0.123(0.030)$ & 30 & 5.0 & 1.00 & 2 & 1 \\
\hline $\mathrm{R} 17$ & $6(386)$ & 90 & $1.000(0.001)$ & $0.055(0.007)$ & 50 & 8.3 & 1.50 & 4 & 1 \\
\hline Population/combined & $79(4,208)$ & 1,190 & $1.000(0.001)$ & $-0.063(0.017)$ & 376 & 4.7 & 1.49 & 44 & 1 \\
\hline
\end{tabular}

$t_{m}$, multilocus outcrossing rate; $t_{m}-t_{s}$, biparental inbreeding estimate.

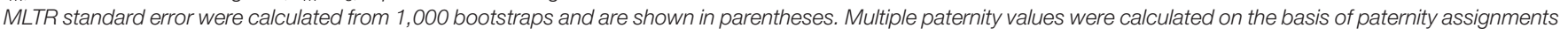
made in CERVUS.

$80 \%$ confidence levels, respectively. The remaining 585 seedlings (49.2\%), which were not assigned to a pollen parent within the study population at $<80 \%$ confidence levels, were assumed to have been sired by an individual in the population that had not been sampled or to be a product of immigrant pollen grains from outside Bawangling population.

Paternity analysis revealed high outcrossing rates (1.000) and multiple paternity, as 36 different sires were identified for 376 seeds in 12 families. The mean number of different sires per fruit ranged from 1.0 to 2.0 , whereas the number of different sires assigned for paternity per tree ranged from 2 to 6 (Figure 2 and Table 3).

\section{Pollen Dispersal Distance}

The 376 outcrossing F1 seedlings with identified male parents were used to estimate the distance distribution of pollen dispersal. $76.1 \%$ of outcrossed pollination events occurred between trees $<200 \mathrm{~m}$ apart, $21.5 \%$ of outcrossed pollination

TABLE 4 | Mating system parameters for Bombax ceiba.

\begin{tabular}{lrc}
\hline Parameters & Estimates & SE \\
\hline Correlation of selfing $\left(r_{t}\right)$ & -0.999 & 0.000 \\
Multilocus correlation of paternity $\left(r_{p}\right)$ & 0.265 & 0.024 \\
Average effective number of pollen donors per maternal & 3.773 & - \\
plant $\left(N_{e p}\right)$ & & \\
Average pollen dispersal distance $(m)$ & 202.89 & 41.01 \\
\hline
\end{tabular}

SE calculated from 1,000 bootstrap replicates by resampling maternal families. events occurred between trees 200-700 m apart, and only $2.4 \%$ of outcrossed pollination events occurred between trees $>1,100 \mathrm{~m}$ apart, respectively (Figure 3). There were significant differences between the observed and the random mating events at 2 of 14 distance classes (all the $P$-values $<0.05$ ), where their proportions (observed/random mating events) were $0.351 / 0.010$ at $0-100 \mathrm{~m}$ and $0.410 / 0.022$ at $100-200 \mathrm{~m}$, respectively. Realized mating events were more frequent than events expected for random mating for the plants $<500 \mathrm{~m}$ apart, indicating a leptokurtic dispersal at this scale (Figure 3A). The mean realized pollen dispersal distance was $202.89 \pm 41.01 \mathrm{~m}$ (mean $\pm \mathrm{SE}$ ) (Table 4). The mean distance between maternal plants and all other plants was $1275.59 \pm 66.39 \mathrm{~m}$. The maximum realized pollen dispersal distance for paternity assignments, made at the 95\% confidence threshold, was 1,140 m (Figure 3B), whereas the distance between maternal plants and their most distant neighbors ranged from 3,172 to $5,958 \mathrm{~m}$.

There was a significant negative correlation $(R=-0.387$, $P=0.007$ ) between the frequency of the outcross mating and the distance between mating pairs (Figure 3B). The overall distribution of pollen dispersal distances was leptokurtosis $(K=0.495)$.

\section{DISCUSSION}

Application of molecular markers for the assignment of paternity in $B$. ceiba has produced the same results that expected for our hypothesis. Our findings show that near-neighbor mating 


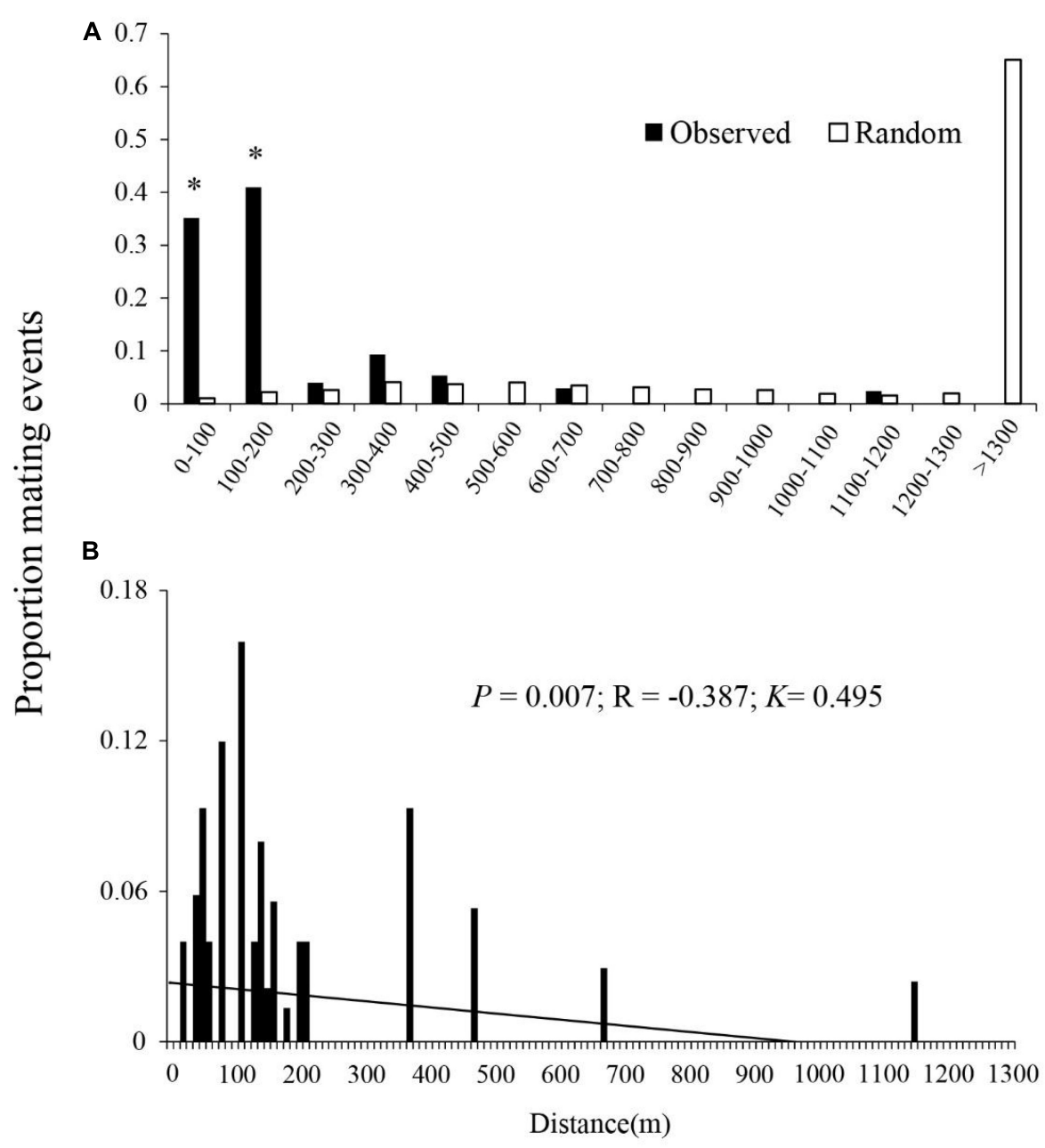

FIGURE 3 | Proportion of realized outcross mating events with distance, showing (A) observed and random outcross pollination events with geographic distance (m) between plant pairs and $(\mathbf{B})$ proportion of mating events with ranked distance between plant pairs. Realized mating events are based on the results of a paternity assignment of seeds $(n=376)$ collected from 12 B. ceiba. Potential mating events are the distances between maternal trees and all the potential sires. *Significant differences $(P<0.001)$ between observed and potential mating events.

is common in generalist-pollinated $B$. ceiba and that the pollen dispersion pattern follows a leptokurtic distribution, which is in accordance with the optimum foraging theory of animals (Pyke, 1984). Our result indicated that B. ceiba possesses strict self-incompatibility with limited pollen dispersal distance and low level of paternity, together with low levels of genetic diversity and a significant spatial genetic structure, which may be consequences of near-neighbor mating caused by restricted flight distance of birds and human disturbances.

\section{Pollen Dispersal Pattern}

Our investigation demonstrated limited-distance pollen dispersal in $B$. ceiba, an observation that differs with previous studies suggesting comparatively greater pollen dispersal of flowering plants by bird pollination (Byrne et al., 2007; Bezemer et al., 2016; Krauss et al., 2017). The mean realized pollen dispersal distance of $B$. ceiba plants pollinated with generalist birds was about $200 \mathrm{~m}$, which is significantly higher than that of Eucalyptus caesia (E. caesia) in a small isolated population (about $80 \mathrm{~m}$ ) (Bezemer et al., 2016), but significantly lower than that of Camellia japonica in a fragmented landscape (about $600 \mathrm{~m}$; Supplementary Table 3; Nakanishi et al., 2020). Pollen dispersal mediated by specialist nectarivorous birds, such as hermit hummingbirds and the word-billed hummingbirds, appears to be farther, as they often move to relatively small, dispersed resources, resulting in the pollen dispersal distance of those plants to be usually greater than $1 \mathrm{~km}$ (Byrne et al., 2007; Supplementary Table 3 ). However, up to $2 \%$ of pollination was recorded to occur in the $B$. ceiba population that was up to $1,100 \mathrm{~m}$ away, around the Baotie village, where human interference has been increasing and plant density has reduced (Figure 2). Our results are consistent with the research on bird-pollinated plants by Kamm et al. (2009) and Côrtes et al. (2013). Their studies have also shown that human interference and low conspecific plant density may increase pollen dispersal 
distances (Kamm et al., 2009) because pollinators have to fly further to reach nearby plants. This also reflects that bird pollination can cope with population fragmentation (Byrne et al., 2007), unlike insect pollination (Ren et al., 2017). Further experiments are required, such as landscape genetic analyses, to falsify this.

Our paternity analysis indicates that pollen dispersal follows an extremely leptokurtic distribution within 1,200 m (Figure 3), which was consistent with the optimal foraging theory. In most cases, pollen dispersal is leptokurtic, with the frequency of mating events decreasing with distance between mating pairs (Pyke, 1980; Proctor et al., 1996). Leptokurtic pollen dispersal by animals may be related to their optimum foraging behavior, in which they feed in order to maximize energy reward relative to energy expenditure (Pyke, 1984). Typically, foraging animals travel between flowers on a single plant and then to a nearby neighbor (Harder and Barrett, 1996). Therefore, optimal foraging behavior of nectar- or pollen-feeding animals is likely to result in localized pollen distribution and biparental inbreeding. There was no significant difference between the observed and the random mating events between plants that were 200-500, 600-700, and 1,100-1,200 m apart, indicating that the likelihood of mating was influenced by, but not, strongly dependent on distance. Conversely, there was a significantly higher proportion of observed potential mating events between plants $0-100$ and $100-200 \mathrm{~m}$ apart, where first-order nearest neighbors and first- to second-order nearest neighbors sired 35 and $41 \%$, respectively, of all the seeds (Figure 3 ), indicating a frequency of short-distance pollen dispersal in excess of random mating expectations. Therefore, we hypothesize that the high population density of $B$. ceiba and disturbances by human activities such as tourism and farming facilitated short-distance flight of birds, resulting in many near random matings in Baoshan village (Figure 2). In addition, higher correlated paternity was always associated with the nearestneighbor pollination, which contributes to magnification of the genetic structuring effects (Krauss et al., 2009). This restricted gene flow resulted in high correlated paternity $\left(r_{p}=0.265\right)$ and may also be the main reason of the SGS of $B$. ceiba at this study site.

\section{Multiple Paternity}

Multiple paternity of $B$. ceiba is observed in this study (Figure 2) and we propose that multiple mating in $B$. ceiba is coupled with a high diversity of sires per maternal tree and facilitated by frequent movement of generalist birds between plants. In flowering plants, multiple paternity is pervasive and occurs when pollen grains from different donors are deposited separately during sequential visits by pollinators or when pollen grains are deposited simultaneously by a single vector that carries pollen grains from several donors (Karron et al., 2006; Llaurens et al., 2008).

The behaviors of generalist birds may contribute to the multiple paternity of $B$. ceiba. In the field, we observed that there are various types of birds that visit $B$. ceiba trees every day, including the large-sized Acridotheres, the mediumsized Pycnonotus and Sturnus, and the small-sized Zosterops (Figure $\mathbf{1}$ and Table 1). They carry pollen grains from various donors to promote multiple paternity. Such results are expected since flowers exposed longer in the pistillate phase of $B$. ceiba (about 4 days) accumulate more pollen on the stigma (Xiang and Ren, 2019). Zosterops spp. makes regular visits to various $B$. ceiba trees to drink nectar and is the main floral visitor in our population (Xiang and Ren, 2019; Table 1).

However, multiple paternity in $B$. ceiba $(1.49 \pm 0.09)$ was markedly lower than those reported in generalist-pollinated E. caesia (4.6 \pm 0.3) (Bezemer et al., 2016) and Banksia hookeriana (29.8 \pm 1.96) (Krauss et al., 2009) in Australia. The lower multiple paternity in $B$. ceiba could be explained by following reasons: (1) Low multiple paternity probably resulted mainly from low fruit setting rate $(3.27 \pm 0.93 \%)$ in $B$. ceiba and restricted flight distance of birds (Table 1), which might cause by human disturbances such as tourism and farming. The blooming B. ceiba attracted many tourists and when $B$. ceiba starts blooming, local farmers transplanted rice seedlings in nearby paddies, resulting in decrease in bird visitation frequency and duration; (2) A massive number of flowers on one tree allows birds to meet their nectar needs without moving frequently between trees, which was proved by the restricted pollen dispersal distance (Figure 2 and Figure 3 ). The high efficiency of pollen removal and low combing behavior of birds (Chen et al., 2019; Song et al., 2019) also made the birds carry a large amount of pollen grains from few pollen donors on their bodies and, thus, have the potential to pollinate multiple ovules in a single visit. One of our observations, where 30 randomly seeds of $>300$ seeds of a plant were all from the same father, supported this possibility (Figure 2 and Table 3); and (3) The investigated plant population is not a completely closed population (Figure 2) and some pollen donors might from unlabeled individuals within study population or nearby populations, which might cause underestimation of multiple paternity in our results.

\section{Obligate Xenogamy and Lower Genetic Diversity}

The self-incompatibility in $B$. ceiba is extremely strict and has been documented in the present and previous studies (Khanduri and Kumar, 2017; Table 2). This strict self-incompatibility in $B$. ceiba might be related to flower traits and the behavior of visiting birds. B. ceiba flowers are large, erect, and bowl shaped, with numerous stamens surrounding the five-branched stigmas (Figure 1B) and, thus, may easily lead to a massive self-pollen deposition on stigmas during the visit of a generalist bird. Therefore, strict self-incompatibility in B. ceiba evolved to ensure outcrossing. This is confirmed by the significant number of aborted fruits observed in the field as well as the withered developing fruits observed in artificial selfpollination treatments.

Our results found a low genetic diversity and obvious SGS in B. ceiba. Normally, nectar-feeding birds assist frequent outcrossing and facilitate pollen dispersal over long distances, which are predicted to result in high genetic diversity and 
weak genetic structure for bird-pollinated plants (Krauss et al., 2017) such as Banksia attenuata in Australia (Krauss et al., 2009), Camellia japonica in Japan (Nakanishi et al., 2020), and Penstemon scariosus (Rodríguez-Peña et al., 2018). In B. ceiba, the low genetic diversity and considerable SGS may be an outcome of the genetic bottlenecks (Supplementary Figure 1) caused by human interferences. $B$. ceiba is widely used in engineering, construction, and composite manufacturing, as it is easily available in form of a fast-growing plant species (Saha et al., 2016). A large number of B. ceiba trees were cut down for economic development and fruits were collected by local people for silk making to make cloth at the beginning of the twentieth century (Zhang and Zhang, 2018), resulting in significant population decline and low level of population regeneration (Zhao et al., 2016; Hassan, 2018). These human disturbances appear to strongly contribute to the low genetic diversity and bottleneck effects of $B$. ceiba.

\section{DATA AVAILABILITY STATEMENT}

The original contributions presented in the study are included in the article/Supplementary Material, further inquiries can be directed to the corresponding author/s.

\section{AUTHOR CONTRIBUTIONS}

W-QX assembled and analyzed the data and wrote the initial draft of the manuscript. PM and LT helped with data analyses, reviewed, and revised the draft. M-XR conceived

\section{REFERENCES}

Barwick, M. (2004). Tropical and Subtropical Trees. Portland: Timber Press.

Bezemer, N., Krauss, S. L., Phillips, R. D., Roberts, D. G., and Hopper, S. D. (2016). Paternity analysis reveals wide pollen dispersal and high multiple paternity in a small isolated population of the bird-pollinated Eucalyptus caesia (Myrtaceae). Heredity 117, 460-471. doi: 10.1038/hdy.2016.61

Breed, M. F., Ottewell, K. M., Gardner, M. G., Marklund, M. H., Dormontt, E. E., and Lowe, A. J. (2015). Mating patterns and pollinator mobility are critical traits in forest fragmentation genetics. Heredity $115,108-114$. doi: 10.1038/hdy. 2013.48

Byrne, M., Elliott, C. P., Yates, C., and Coates, D. J. (2007). Extensive pollen dispersal in a bird-pollinated shrub, Calothamnus quadrifidus, in a fragmented landscape. Mol. Ecol. 16, 1303-1314. doi: 10.1111/j.1365-294X.2006.03 204.x

Campbell, D. R. (1998). Multiple paternity in fruits of Ipomopsis aggregata (Polemoniaceae). Am. J. Bot. 85, 1022-1027. doi: 10.2307/2446369

Chen, K. H., Lu, J. Y., and Wang, C. N. (2019). Effective pollination of Aeschynanthus acuminatus (Gesneriaceae) by generalist passerines, in sunbird-absent East Asia. Sci. Rep. 9, 1-12. doi: 10.1038/s41598-019-5 3035-2

Coimbra, G., Araujo, C., Bergamo, P. J., Freitas, L., and Rodríguez-Gironés, M. A. (2020). Flower conspicuousness to bees across pollination systems: a generalized test of the bee-avoidance hypothesis. Front. Plant Sci. 11:1453. doi: $10.3389 /$ fpls. 2020.558684

Côrtes, M. C., Uriarte, M., Lemes, M. R., Gribel, R., John Kress, W., Smouse, P. E., et al. (2013). Low plant density enhances gene dispersal in the Amazonian understory herb Heliconia acuminata. Mol. Ecol. 22, 5716-5729. doi: 10.1111/ mec. 12495 the idea, designed this study, and critically reviewed the manuscript. All the authors contributed to the final version of the manuscript.

\section{FUNDING}

This study was supported by the Key Science and Technology Program of Hainan Province (No. ZDKJ202008), the National Natural Science Foundation of China (No. 41871041), and the Hainan Provincial Innovative Research Projects of Postgraduates (No. Hyb2019-03).

\section{ACKNOWLEDGMENTS}

We thank Moqiang Zhao of the National Park of Hainan Tropical Rainforest, China, for the help with collecting samples. We are also grateful to Tao $\mathrm{Lu}$ and Yichao Chen for their kind assistance in mapping the trees and collecting samples. We thank Zhe Zhang of Hainan University and Junyi Ding of Shandong Agricultural University for their help in data analysis. Finally, we would like to thank all the referees for their valuable comments on the manuscript.

\section{SUPPLEMENTARY MATERIAL}

The Supplementary Material for this article can be found online at: https://www.frontiersin.org/articles/10.3389/fpls.2022. 806217/full\#supplementary-material

de Waal, C., Anderson, B., and Barrett, S. C. (2012). The natural history of pollination and mating in bird-pollinated Babiana (Iridaceae). Ann. Bot. 109, 667-679. doi: 10.1093/aob/mcr172

Di Rienzo, A., Peterson, A. C., Garza, J. C., Valdes, A. M., Slatkin, M., and Freimer, N. B. (1994). Mutational processes of simple-sequence repeat loci in human populations. Proc. Natl. Acad. Sci. 91, 3166-3170. doi: 10.1073/pnas.91.8.3166

Doyle, J. J. (1990). Isolation of plant DNA from fresh tissue. Focus 1990, $13-15$.

Gu, L., Luo, Z., Zhang, D., and Renner, S. S. (2010). Passerine pollination of Rhodoleia Championii (Hamamelidaceae) in subtropical china. Biotropica 42, 336-341. doi: 10.1111/j.1744-7429.2009.00585.x

Harder, L. D., and Barrett, S. C. (1996). "Pollen dispersal and mating patterns in animal-pollinated plants," in Floral biology, ed. M. Percival (Boston, MA: Springer), 140-190. doi: 10.1093/aob/mcl119

Hardy, O. J., and Vekemans, X. (2002). SPAGeDi: a versatile computer program to analyse spatial genetic structure at the individual or population levels. Mol. Ecol. Notes 2, 618-620. doi: 10.1046/j.1471-8286.2002.00305.x

Hassan, M. O. (2018). Leaf litter of Bombax ceiba L. threatens plant cover and floristic diversity in a new urban ecosystem. Flora 242, 22-30. doi: 10.1016/j. flora.2018.03.004

Higgins, P. J., and Peter, J. M. (2002). Handbook of Australian, New Zealand and Antarctic Birds. Volume 6: Pardalotes to Shrike-thrushes. Melbourne: Oxford University Press.

Higgins, P. J., Peter, J. M., and Cowling, S. J. (2006). Handbook of Australian, New Zealand and Antarctic Birds. Volume 7: Boatbill to Starlings. Melbourne: Oxford University Press.

Huang, Z. H., Luo, W. H., Huang, S. X., and Huang, S. Q. (2018). Sunbirds serve as major pollinators for various populations of Firmiana kwangsiensis, a tree endemic to South China. J. Systemat. Evolut. 56, 243-249. doi: 10.1111/jse.12311 
Jain, V., Verma, S. K., Sharma, S. K., and Katewa, S. S. (2011). Bombax ceiba Linn.: As an umbrella tree species in forests of southern Rajasthan, India. Res. J. Environ. Sci. 5:722. doi: 10.3923/rjes.2011.722.729

Ju, M. M., Ma, H. C., Xin, P. Y., Zhou, Z. L., and Tian, B. (2015). Development and characterization of EST-SSR markers in Bombax ceiba (Malvaceae). Applicat. Plant Sci. 3:1500001. doi: 10.3732/apps.1500001

Kalinowski, S. T., Taper, M. L., and Marshall, T. C. (2007). Revising how the computer program CERVUS accommodates genotyping error increases success in paternity assignment. Mol. Ecol. 16, 1099-1106. doi: 10.1111/j.1365-294X. 2007.03089.x

Kamm, U., Rotach, P., Gugerli, F., Siroky, M., Edwards, P., and Holderegger, R. (2009). Frequent long-distance gene flow in a rare temperate forest tree (Sorbus domestica) at the landscape scale. Heredity 103, 476-482. doi: 10.1038/hdy. 2009.70

Karron, J. D., Mitchell, R. J., and Bell, J. M. (2006). Multiple pollinator visits to Mimulus ringens (Phrymaceae) flowers increase mate number and seed set within fruits. Am. J. Bot. 93, 1306-1312. doi: 10.3732/ajb.93.9.1306

Khanduri, V. P., and Kumar, K. S. (2017). Reproductive effort and success in Bombax ceiba L. in a tropical forest of Mizoram, Indo-Burma region of NorthEast India. Brazil. J. Bot. 40, 157-166. doi: 10.1007/s40415-016-0327-2

Krauss, S. L., He, T., Barrett, L. G., Lamont, B. B., Enright, N. J., Miller, B. P., et al. (2009). Contrasting impacts of pollen and seed dispersal on spatial genetic structure in the bird-pollinated Banksia hookeriana. Heredity 102, 274-285. doi: 10.1038/hdy.2008.118

Krauss, S. L., Phillips, R. D., Karron, J. D., Johnson, S. D., Roberts, D. G., and Hopper, S. D. (2017). Novel consequences of bird pollination for plant mating. Trends Plant Sci. 22, 395-410. doi: 10.1016/j.tplants.2017.03.005

Li, Q. S., Li, W. D., Luo, X., and Ma, H. C. (2016). The avian diversity of Bombax ceiba flower visitors in Nujiang Valley, Yunnan. J. Southw. For. Univers. 36, 174-180. doi: 10.11929/j.issn.2095-1914.2016.03.030

Linhart, Y. B., and Feinsinger, P. (1980). Plant-hummingbird interactions: effects of island size and degree of specialization on pollination. J. Ecol. 1980, 745-760. doi: $10.2307 / 2259454$

Llaurens, V., Castric, V., Austerlitz, F., and Vekemans, X. (2008). High paternal diversity in the self-incompatible herb Arabidopsis halleri despite clonal reproduction and spatially restricted pollen dispersal. Mol. Ecol. 17, 1577-1588. doi: 10.1111/j.1365-294X.2007.03683.x

Llorens, T. M., Byrne, M., Yates, C. J., Nistelberger, H. M., and Coates, D. J. (2012). Evaluating the influence of different aspects of habitat fragmentation on mating patterns and pollen dispersal in the bird-pollinated Banksia sphaerocarpa var. caesia. Mol. Ecol. 21, 314-328. doi: 10.1111/j.1365-294X.2011.05396.x

Loiselle, B. A., Sork, V. L., Nason, J., and Graham, C. (1995). Spatial genetic structure of a tropical understory shrub, Psychotria officinalis (Rubiaceae). Am. J. Bot. 82, 1420-1425. doi: 10.1002/j.1537-2197.1995.tb12679.x

Marshall, T. C., Slate, J. B. K. E., Kruuk, L. E. B., and Pemberton, J. M. (1998). Statistical confidence for likelihood-based paternity inference in natural populations. Mol. Ecol. 7, 639-655. doi: 10.1046/j.1365-294x.1998.00374.x

Nakanishi, A., Takeuchi, T., Ueno, S., Nishimura, N., and Tomaru, N. (2020). Spatial variation in bird pollination and its mitigating effects on the genetic diversity of pollen pools accepted by Camellia japonica trees within a population at a landscape level. Heredity 124, 170-181. doi: 10.1038/s41437-019-0262-7

Piry, S., Luikart, G., and Cornuet, J. M. (1999). Computer note. BOTTLENECK: a computer program for detecting recent reductions in the effective size using allele frequency data. J. Heredity 90, 502-503. doi: 10.1093/jhered/90.4.502

Proctor, M., Yeo, P., and Lack, A. (1996). The natural history of pollination. Portland, OR: Timber Press.

Pyke, G. H. (1980). The foraging behaviour of Australian honeyeaters: a review and some comparisons with hummingbirds. Austral. J. Ecol. 5, 343-369. doi: 10.1111/j.1442-9993.1980.tb01258.x

Pyke, G. H. (1984). Optimal foraging theory: a critical review. Annu. Rev. Ecol. Systemat. 15, 523-575. doi: 10.1146/annurev.es.15.110184.002515

R Core Team (2013). R: A language and environment for statistical computing. Vienna: R Core Team.

Raju, A. J. S. (2005). Passerine bird pollination and seed dispersal in Woodfordia floribunda Salisb. (Lythraceae), a common low altitude woody shrub in the Eastern Ghats forests of India. Ornithol. Sci. 4, 103-108. doi: 10.2326/osj.4.103

Raju, A. J. S., Rao, S. P., and Rangaiah, K. (2005). Pollination by bats and birds in the obligate outcrosser Bombax ceiba L.(Bombacaceae), a tropical dry season flowering tree species in the Eastern Ghats forests of India. Ornithol. Sci. 4, 81-87. doi: 10.2326/osj.4.81

Raymond, M., and Rousset, F. (1995). Genepop (Version-1.2): populationgenetics software for exact tests and ecumenicism. J. Heredity 86, 248-249.

Ren, M. X., Cafasso, D., Cozzolino, S., and Pinheiro, F. (2017). Extensive genetic differentiation at a small geographical scale: reduced seed dispersal in a narrow endemic marsh orchid, Anacamptis robusta. Bot. J. Linnean Soc. 183, 429-438. doi: 10.1093/botlinnean/bow017

Ritland, K. (2002). Extensions of models for the estimation of mating systems using $\mathrm{n}$ independent loci. Heredity 88, 221-228. doi: 10.1038/sj.hdy.68 00029

Rodríguez-Peña, R. A., Johnson, R. L., Johnson, L. A., Anderson, C. D., Ricks, N. J., Farley, K. M., et al. (2018). Investigating the genetic diversity and differentiation patterns in the Penstemon scariosus species complex under different sample sizes using AFLPs and SSRs. Conserv. Genet. 19, 1335-1348. doi: 10.1007/ s10592-018-1103-6

Roguz, K., Bajguz, A., Gołębiewska, A., Chmur, M., Hill, L., Kalinowski, P., et al. (2018). Functional diversity of nectary structure and nectar composition in the genus Fritillaria (Liliaceae). Front. Plant Sci. 9:1246. doi: 10.3389/fpls.2018. 01246

Roguz, K., Hill, L., Roguz, A., and Zych, M. (2021). Evolution of bird and insect flower traits in Fritillaria L. (Liliaceae). Front. Plant Sci. 12:484. doi: 10.3389/ fpls.2021.656783

Saha, P., Chowdhury, S., Manna, S., Roy, D., Adhikari, B., and Thomas, S. (2016). New biobased surface treatment to improve strength and durability of Bombax ceiba. ACS Sustain. Chem. Engine. 4, 76-84. doi: 10.1021/acssuschemeng. $5 \mathrm{~b} 01057$

Schulke, B., and Waser, N. M. (2001). Long-distance pollinator flights and pollen dispersal between populations of Delphinium nuttallianum. Oecologia 127, 239-245. doi: 10.1007/s004420000586

Sekercioglu, C. H. (2006). Increasing awareness of avian ecological function. Trends Ecol. Evol. 21, 464-471. doi: 10.1016/j.tree.2006.05.007

Siegel, S. (1956). Nonparametric Statistics for the Behavioral Sciences. New York, NY: McGraw Hill.

Sokal, R., and Rohlf, J. (1995). Biometry: The principles and practices of statistics in biological research ( $3 r d)$. New York, NY: W.H. Freeman and Company.

Song, Y., Huang, Z., and Huang, S. (2019). Pollen aggregation by viscin threads in Rhododendron varies with pollinator. New Phytol. 221, 1150-1159. doi: 10. 1111/nph.15391

Song, Z. P., Xu, X., Wang, B., Chen, J. K., and Lu, B. R. (2003). Genetic diversity in the northernmost oryza rufipogon populations estimated by SSR markers. Theoret. Appl. Genet. 107:1492. doi: 10.1007/s00122-003-1380-3

Southerton, S. G., Birt, P., Porter, J., and Ford, H. A. (2004). Review of gene movement by bats and birds and its potential significance for eucalypt plantation forestry. Austral. For. 67, 44-53. doi: 10.1080/00049158.2004. 10676205

Steenhuisen, S. L., Van der Bank, H., and Johnson, S. D. (2012). The relative contributions of insect and bird pollinators to outcrossing in an African Protea (Proteaceae). Am. J. Bot. 99, 1104-1111. doi: 10.3732/ajb.1100535

Stiles, F. G. (1975). Ecology, flowering phenology, and hummingbird pollination of some Costa Rican Heliconia species. Ecology 56, 285-301. doi: 10.2307/19 34961

Stiles, F. G. (1978). Ecological and evolutionary implications of bird pollination. Am. Zool. 18, 715-727. doi: 10.1093/icb/18.4.715

Van Oosterhout, C., Hutchinson, W. F., Wills, D. P., and Shipley, P. (2004). MICRO-CHECKER: software for identifying and correcting genotyping errors in microsatellite data. Mol. Ecol. Notes 4, 535-538. doi: 10.1111/j.1471-8286. 2004.00684.x

Wee, A. K., Low, S. Y., and Webb, E. L. (2015). Pollen limitation affects reproductive outcome in the bird-pollinated mangrove Bruguiera gymnorrhiza (Lam.) in a highly urbanized environment. Aquat. Bot. 120, 240-243. doi: 10.1016/j.aquabot.2014.09.001

Wester, P., and Claßen-Bockhoff, R. (2006). Bird pollination in South African Salvia species. Flora 201, 396-406. doi: 10.1016/j.flora.2005.07.016

Wu, Q., Zang, F., Ma, Y., Zheng, Y., and Zang, D. (2020). Analysis of genetic diversity and population structure in endangered Populus wulianensis based on 18 newly developed EST-SSR markers. Glob. Ecol. Conserv. 24:e01329. 
Xiang, W. Q., and Ren, M. X. (2019). Adaptive significance of yellow flowered Bombax ceiba (Malvaceae). Biodivers. Sci. 27, 373-379. doi: 10.17520/biods. 2019003

Zhang, H. M., and Zhang, Y. (2018). On the Representation of Natural Exploration Intelligence in the Traditional Handicraft of the Li People. J. Hainan Normal Univers. 31, 140-144. doi: 10.16061/j.cnki.cn46-1076/c.2018.05.023

Zhao, G. J., Xu, X. L., Ma, H. C., Huang, D., Yang, J. J., Shu, H. H., et al. (2016). Causes of difficulties with natural regeneration of a Bombax ceiba population in Hong-He dry-hot valleys (DHV). Acta Ecol. Sin. 2016, 1342-1351. doi: 10.5846/ stxb201407161446

Zhao, Z. J. (2001). A Handbook of the Birds of China. Changchun: Jilin Science and Technology Publishing House.

Zhou, Z., Ma, H., Lin, K., Zhao, Y., Chen, Y., et al. (2015). RNA-seq Reveals Complicated Transcriptomic Responses to Drought Stress in a Nonmodel Tropic Plant, Bombax ceiba L. Evolution. Bioinform. 11, 27-37. doi: 10.4137/ EBO.S20620
Conflict of Interest: The authors declare that the research was conducted in the absence of any commercial or financial relationships that could be construed as a potential conflict of interest.

Publisher's Note: All claims expressed in this article are solely those of the authors and do not necessarily represent those of their affiliated organizations, or those of the publisher, the editors and the reviewers. Any product that may be evaluated in this article, or claim that may be made by its manufacturer, is not guaranteed or endorsed by the publisher.

Copyright (c) 2022 Xiang, Malabrigo, Tang and Ren. This is an open-access article distributed under the terms of the Creative Commons Attribution License (CC BY). The use, distribution or reproduction in other forums is permitted, provided the original author(s) and the copyright owner(s) are credited and that the original publication in this journal is cited, in accordance with accepted academic practice. No use, distribution or reproduction is permitted which does not comply with these terms. 